\title{
High Density Photovoltaic
}

\author{
R. Haigh \\ G. Jacobson \\ S. Wojtczuk
}

October 14, 1997

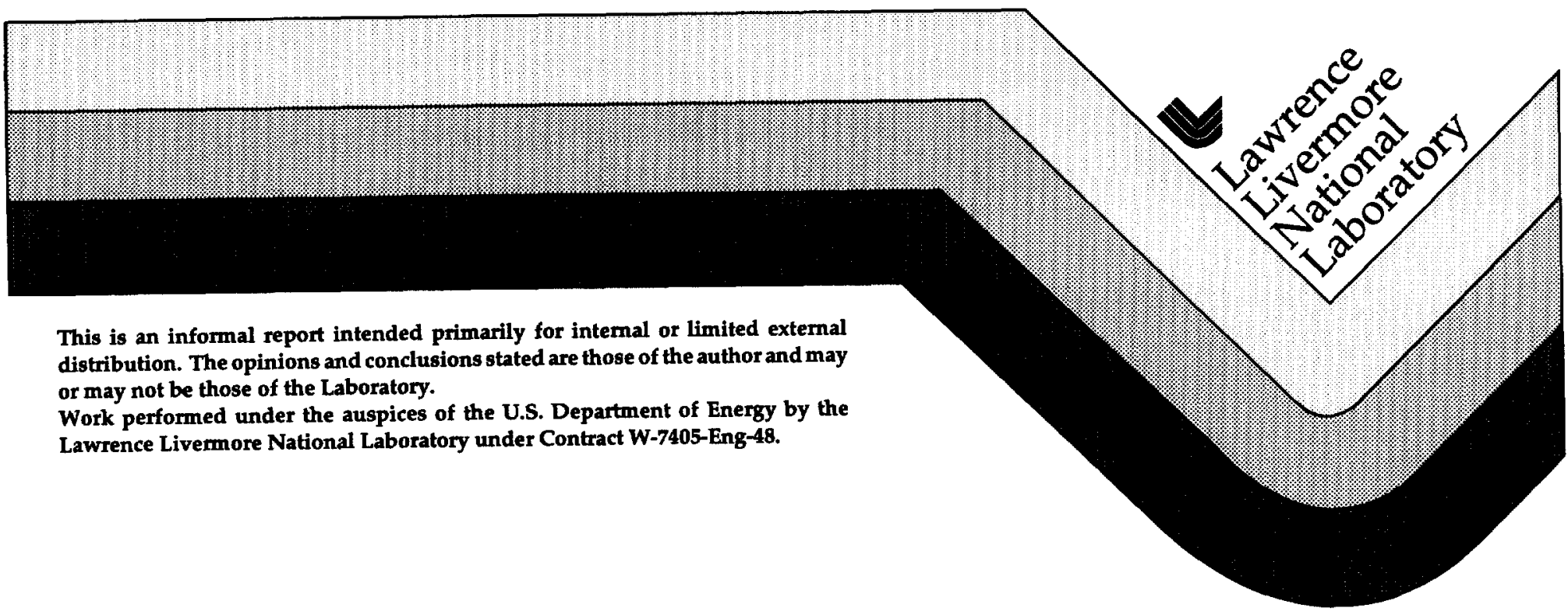




\section{DISCLAIMER}

This document was prepared as an account of work sponsored by an agency of the United States Government. Neither the United States Government nor the University of California nor any of their employees, makes any warranty, express or implied, or assumes any legal liability or responsibility for the accuracy. completeness, or usefulness of any information, apparatus, product, or process disclosed, or represents that its use would not in fringe privately owned rights. Reference herein to any specific commercial product, process, or service by trade name, trademark, manufacturer, or otherwise, does not necessarily constitute or imply its endorsement, recommendation, or favoring by the United States Government or the University of California. The views and opinions of authors expressed herein do not necessarily state or reflect those of the United States Government or the University of California, and shall not be used for advertising or product endorsement purposes.

This report has been reproduced directly from the best available copy.

Available to DOE and DOE contractors from the Office of Scientific and Technical Information

P.O. Box 62, Oak Ridge, TN 37831

Prices available from (615) 576-8401, FTS 626-8401

Available to the public from the National Technical Information Service

U.S. Department of Commerce

5285 Port Royal Rd.,

Springfield, VA 22161 


\title{
igh-Density Photovoltaics
}

\author{
Ronald E. Haigh and Gerard F. Jacobson \\ Defense Sciences Engineering Division \\ Electronics Engineering
}

Steve Wojtczuk

Spire Corporation

Bedford, Massachusetts

Photovoltaic technology can directly generate high voltages in a solid state material through the series interconnect of many photovoltaic diodes. We are investigating the feasibility of developing an electrically isolated, high-voltage power supply using miniature photovoltaic devices that convert optical energy to electrical energy.

\section{Introduction}

Our goals this year were to demonstrate the feasibility of generating high voltages from a monolithic array of solid state photovoltaic diodes that have been connected in series, and to develop a fiber-optic illumination scheme (Fig. 1). High voltages developed directly from series interconnected photovoltaic cells are an alternative to transformers and other voltage step-up technologies.

The photovoltaic device is electrically isolated from the laser diode by the silica optical fiber. Electrical isolation is beneficial for applications requiring highvoltage stand-off, lightning and EMI suppression, as well as spark suppression in volatile environments such as mines, fuel tanks, and high explosives. The solid state nature of photovoltaic diode arrays allows them to be incorporated into low profile hybrid circuits for programmatic and commercial applications.

The photovoltaics were designed for maximum efficiency when illuminated with a near infrared laser beam, in contrast to photovoltaics optimized for solar illumination. For a series-connected photovoltaic diode array to function efficiently, each diode in the array must be illuminated uniformly. We have developed a unique scheme based on fiber-optic diffuser technology to address the illumination issue.

\section{Progress}

Our efforts focused on developing miniature arrays of photovoltaic diodes in GaAs, due to the high efficiency of this material at the wavelength of our $800 \mathrm{~nm}$ laser diode. One hundred photovoltaic diodes arranged in a $2 \times 50$ array with a $110-\mu \mathrm{m}$ pitch were monolithically interconnected in series (Fig. 2a). The individual diodes were $220 \mu \mathrm{m} \times 50 \mu \mathrm{m}$ and the array was $0.8 \mathrm{~mm} \times 5.8 \mathrm{~mm}$. Our arrays have achieved more than a 10 -fold improvement in voltage per unit area compared to the smallest reported photovoltaic array in this voltage class. ${ }^{1}$

The individual diodes on a semi-insulating substrate are electrically isolated by trenches etched around each device (Fig. 2b). Photons entering the trench regions are absorbed in the semi-insulating substrate, the effects of which are discussed later, and do not contribute to useful energy conversion. From Fig. 2a, it is apparent that

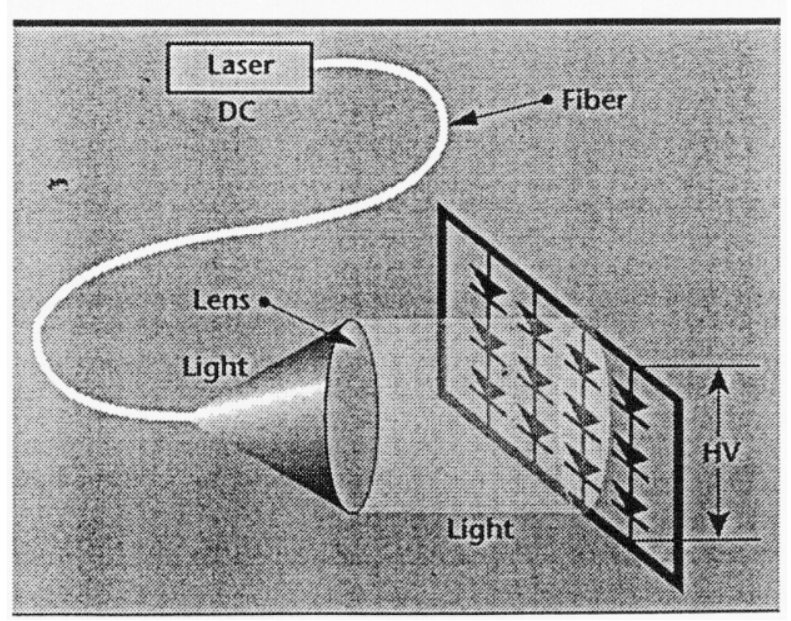

Figure 1. Schematic illustration of fiber-optic illumination system. 
the trench regions are a significant fraction of the total active device area. To improve the efficiency of the array, the ratio of trench area to active area should be reduced.

\section{Photovoltalc Device Structure}

The series-interconnected array of mesa-isolated photovoltaic devices was developed in a collaboration with Spire Corporation. The metal organic chemical vapor deposition (MOCVD) epitaxial material growth and device processing was performed at Spire.

The basic device structure is an extension of lowvoltage multi-junction devices developed earlier by Sandia National Laboratories ${ }^{2}$ and those developed commencially by Spire Corporation. The photovoltaic diodes are $p$-on-n devices, due to higher mobility of the electrons in the $\mathrm{n}$ material. The $\mathrm{I}^{2} \mathrm{R}$ energy loss due to the sheet resistance of the $p$ material on the upper layer is minimized by incorporating a thin metal finger on the p contact along the length of the device.

The epitaxial structure consists of a heavily $p$ doped GaAs emitter layer on a thick n-type GaAs base layer with $p+$ and $n+$ contact layers on a semiinsulating substrate (Table 1). An AIGaAs etch stop layer is incorporated into the epitaxial structure so

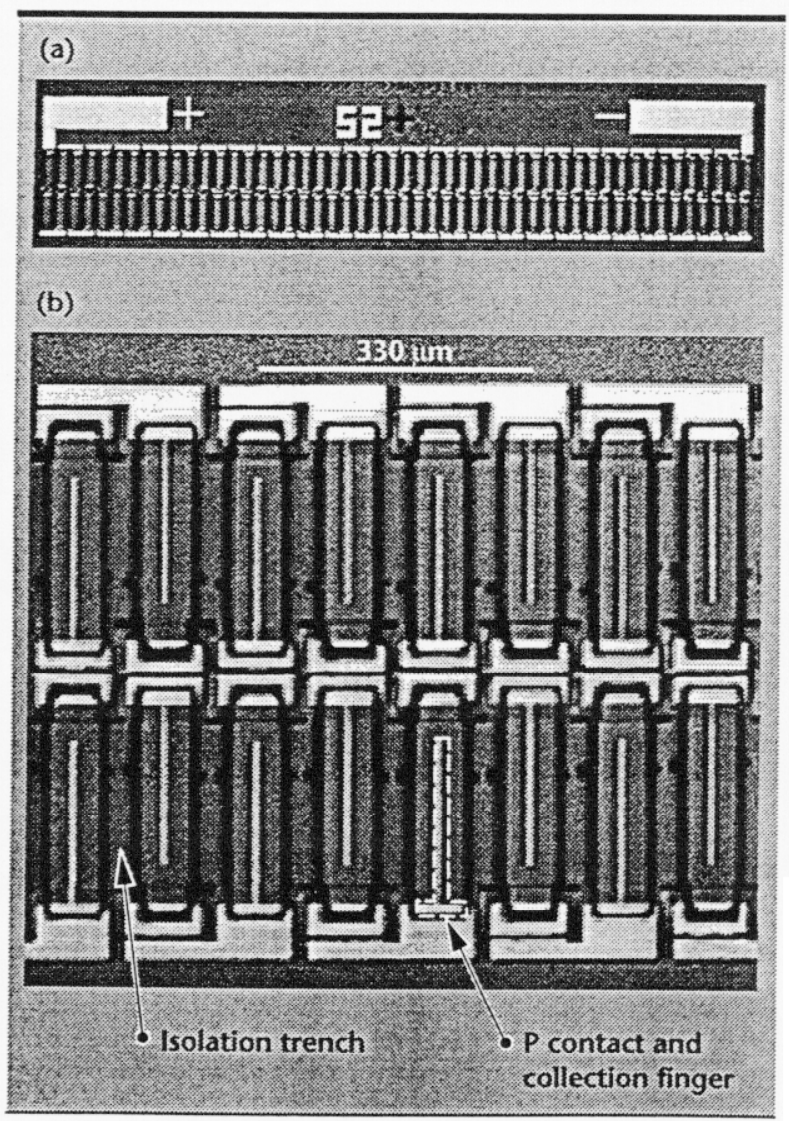

Figure 2. (a) Section of photovoltaic diode array; (b) individual diodes on a semi-insulating substrate. that the etch depth to the buried $n+$ contact can be more accurately controlled during processing. The AIGaAs layer also serves as a back-surface field, which improves the efficiency of the cell. ${ }^{3}$ Finally a single-layer of quarter-wavelength silicon nitride anti-reflection coating, optimized for $850 \mathrm{~nm}$, is deposited on top of the device. The absorption depth of $800 \mathrm{~nm}$ photons is about $1 \mu \mathrm{m}$ in GaAs so the thickness of the emitter and base layers absorbs $99 \%$ of the available photons.

Individual diode open-circuit voltages as high as $1.1 \mathrm{~V}$ and short circuit currents of $0.4 \mathrm{~mA}$, corresponding to a responsivity of $0.4 \mathrm{~A} / \mathrm{W}$, were measured at an illumination intensity of $4 \mathrm{~W} / \mathrm{cm}^{2}$. Short circuit currents of $7.75 \mathrm{~mA}$ were measured at an Illumination intensity of $80 \mathrm{~W} / \mathrm{cm}^{2}$, corresponding to a degraded responsivity of $0.387 \mathrm{~A} / \mathrm{W}$.

Individual diode open-circuit voltages as high as $1.1 \mathrm{~V}$ and short circuit responsivity of $0.4 \mathrm{~A} / \mathrm{W}$ were measured at an illumination intensity of $4 \mathrm{~W} / \mathrm{cm}^{2}$. The responsitivity of the device could be improved by incorporating an $\mathrm{Al}_{\mathrm{x}} \mathrm{Ga}_{(1-\mathrm{x})} \mathrm{As}$ window layer on top of the emitter to reduce the losses due to surface recombination. ${ }^{4}$ Photovoltaics with an $\mathrm{Al}_{x} \mathrm{Ga}_{(1-\mathrm{x})} \mathrm{As}$ window layer have been reported with a responsitivity of $0.6 \mathrm{~A} / \mathrm{W}$. The window layer was intentionally omitted from our devices to reduce the complexity of this developmental effort.

Initially the 100-element photovoltaic array produced an output voltage of only $15 \mathrm{~V}$ when illuminated with a laser source. It was determined experimentally that photoconductive currents caused by photon absorption in the isolation trenches between the devices shunted the array. An analytical model of the shunting has since been developed to confirm the experimental results. Earlier work on similar devices indicated that the photoconductive shunting effect in the semi-insulating substrate was negligible. ${ }^{2}$

Table 1. Epitaxial layers.

\begin{tabular}{|c|c|c|}
\hline Layer & Material & Thickness \\
\hline AR coating & $\mathrm{SI}_{3} \mathrm{~N}_{4}$ & $100 \mathrm{~nm}$ \\
\hline p contact layer & GaAs & $0.1 \mu \mathrm{m}$ \\
\hline Emitter & GaAs & $0.1 \mu \mathrm{m}$ \\
\hline Base & GaAs & $3.0 \mathrm{\mu m}$ \\
\hline Etch Stop/BSF & AlGaAs & $0.2 \mu \mathrm{m}$ \\
\hline n contact layer & GaAs & $3.0 \mu \mathrm{m}$ \\
\hline Substrate & GaAs-SI & $635 \mu \mathrm{m}$ \\
\hline
\end{tabular}


After applying an opaque material in the isolation trenches between the active devices, the output voltage of the array increased to $90 \mathrm{~V}$. The I-V curve for the photovoltaic array after the opaque material was applied is shown in Fig. 3. The kink in the curve is due to a non-ideal ohmic contact. This was caused by an inability to sufficiently dope the $n$ contact material at a high enough level, a known limitation at the time the material was grown for these devices.

New material has since been grown that will correct the ohmic contact problem. Furthermore, two approaches to resolve the photoconductive shunting effect are being pursued. In the first approach, metal interconnects are being patterned in the trenches between the devices. The second approach involves incorporating a buried $\mathrm{p}$ layer between the diode and the substrate in an attempt to electrically isolate the diode and the substrate via a potential barrier.

The design of the $2 \times 50$ array was conservative enough to achieve high array yields. A more aggressive design, which doubled the device density, failed to produce any useful devices due to problems in achieving uniform etching during the mesa-isolation process step. Larger arrays of monolithically interconnected devices appear feasible with diodes on the dimension scale of the $2 \times 50$ array without further investment in process development.

\section{Modeling}

A semiconductor modeling tool, PC1D, developed at the Photovoltaics Special Research Centre at the University of New South Wales in Sydney, Australia

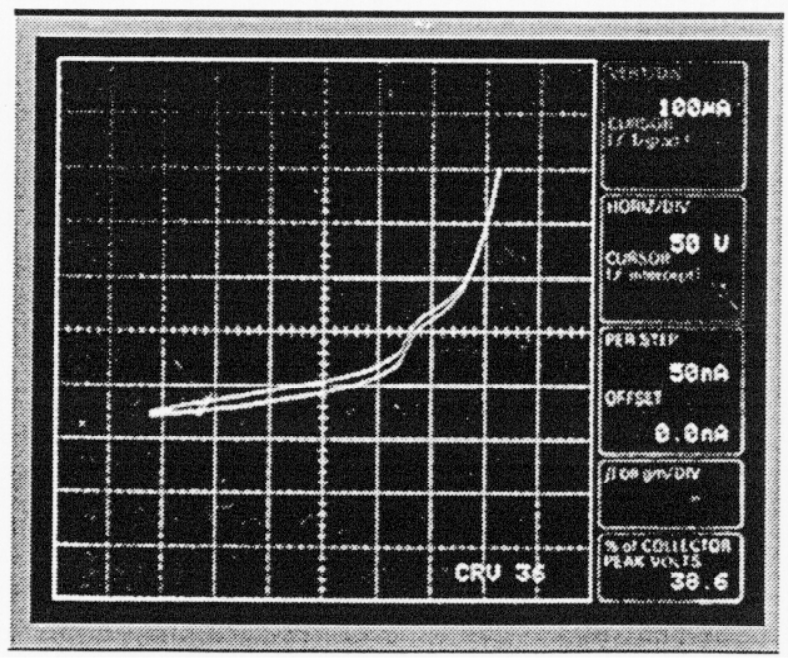

Figure 3. Current vs voltoge curve for photovoltaic array ofter application of opaque material. was used to model performance of the photovoltaic device based on its epitaxial structure and illumination conditions. PC1D is a computer program, written for IBM-compatible personal computers, that solves the fully coupled nonlinear equations for the quasi-one-dimensional transport of electrons and holes in crystalline semiconductor devices, with an emphasis on photovoltaic devices.

The code simulates the performance of the photovoltaic devices, so that the device structures can be optimized. The modeling tool also gives insight into the device performance under different illumination and environmental conditions. For instance we can determine how the illumination wavelength, intensity, or temperature affects the output characteristics of the device.

Shown in Fig. 4 are the simulated I-V curves at two different ambient temperatures, $300 \mathrm{~K}$ and $400 \mathrm{~K}$, for the photovoltaic device under monochromatic $800 \mathrm{~nm}$ illumination. The temperature dependence of the open circuit voltage, which may vary as much as $15 \%$, can result in significant voltage changes for large photovoltaic arrays. The simulation agrees well with experimental results of the device temperature dependence of $1.5 \mathrm{mV} / \mathrm{C}^{2}{ }^{2}$

\section{Laser Illumination}

The output current from a series-connected photovoltaic array is determined by the photovoltaic diode that generates the least amount of current. For arrays with similar diode characteristics, it is necessary to illuminate all the photovoltaic devices uniformly in the linear array, otherwise the output current of the array will be restricted.

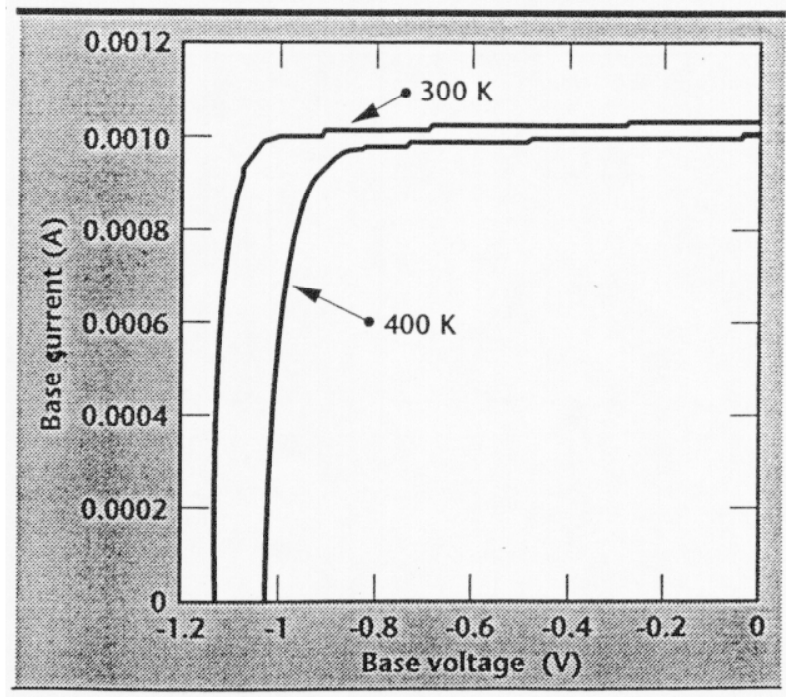

Figure 4. Simulated temperature dependence of a single photovoltaic diode. 


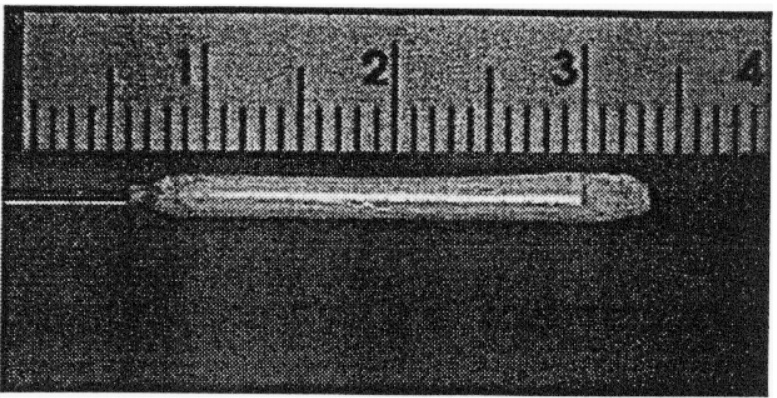

Figure 5. Cylindrical diffuser emitting light from a fiber coupled HeNe laser.

Due to our array geometry, $0.8 \mathrm{~mm} \times 5.8 \mathrm{~mm}$, our illumination system must generate a uniform intensity top hat profile with a high aspect ratio, $10: 1$. To address this issue, we modified a commercially available fiber-optic diffuser to illuminate the photovoltaic array. The diffuser approach was pursued because it is compact, which substantially decreases the packaging size.

A reflective dielectric coating was applied around the perimeter of the diffuser, leaving only a small slit along the length of the diffuser uncoated for the light to exit (Fig. 5). Approximately $50 \%$ of the light entering the fiber exits the diffuser within the small output slit. An intensity uniformity along the length of the diffuser of $\pm \% 15$ was measured with a CCD camera.

\section{Future Work}

This year we demonstrated a monolithic photovoltaic array with a 90-V output. We believe higher voltages are obtainable either monolithically or by series connection of multiple devices using hybrid micro-circuit fabrication techniques.

Future research on improving the efficiency of the photovoltaic array and reducing its size even further is possible.

\section{Acknowledgments}

The support and encouragement of D. O'Brien, R. Clough, and K. Freytag are greatly appreciated.

\section{References}

1. Sakakibara, T., H. Izu, H. Tarat, and S. Kiyama (1997), "Development of High Voltage Photovoltalc Micro-Devices for Driving Micro Actuators." IEICE Transactions on Electronics, Feb., Vol. E80-C. (2), pp. 309-313.

2. Rose, B. (1992), Monolithic, Series Connected GaAs Photovoltalc Power Converters for Optoelectronic Component Applications, Sandia National Laboratory, Livermore, CA. September (SAND-92-1534).

3 MacMillian, H. F., H. C. Hamaker, N. R. Kaminar, and M. S. Kuryla (1988), “28\% Efficient GaAs Concentrator Solar Cells." 20th IEEE Photovoltaic Specialists Conf.. Sept., Vol. 1, pp. 462-468.

4. Kamath, G. S., J. Ewan, and R. C. Knechtll (1977). "Large-area high-efficlency (AIGa) As-GaAs solar cells," IEEE Transactions on Electron Devices, April. Vol. ED-24, pp. 473-5. 


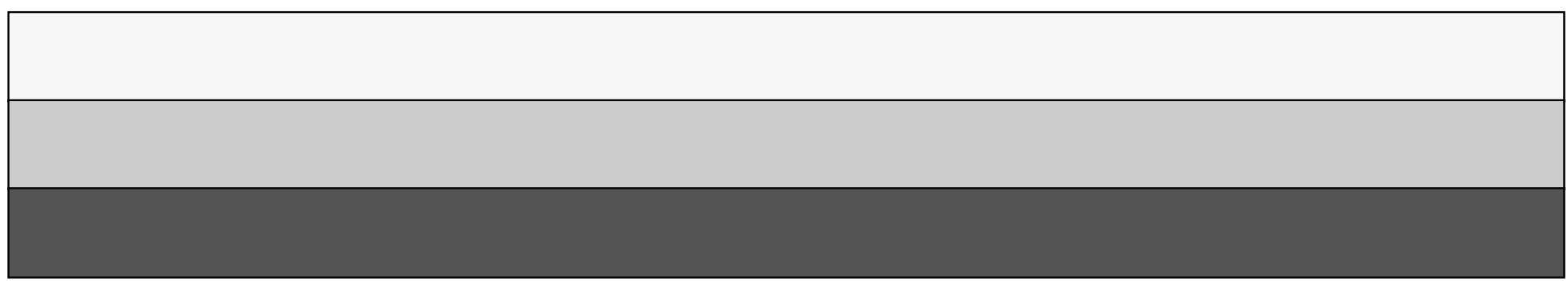

